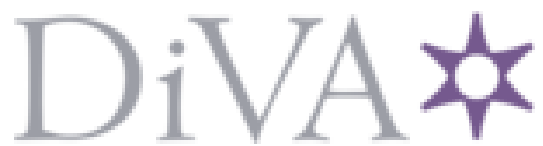

http://www.diva-portal.org

This is the published version of a paper published in .

Citation for the original published paper (version of record):

Tavallaey, S S. (1998)

Dynamic and acoustic properties of beams of composite material

The Journal of the Acoustical Society of America, 103(5): 2929-2929

https://doi.org/10.1121/1.422148

Access to the published version may require subscription.

N.B. When citing this work, cite the original published paper.

Permanent link to this version:

http://urn.kb.se/resolve?urn=urn:nbn:se:kth:diva-298592 


\title{
Dynamic and Acoustic Properties of Beams of Composite Material
}

\author{
Shiva Sander Tavallaey \\ MWL, Dept. of Vehicle Engineering, KTH, 10044 STOCKHO LM, Sweden
}

\section{INTRO DUCTION}

Sand wich materials find numerous applications where high strength and low-weight are important criteria. In this paper, in order to investigate dynamic behavior of sandwich-beam with different boundary conditions, measurements have been carried out. Free-free and clamped-clamped boundary conditions were included. The results indicate that the boundary conditions have a considerable influence on dynamical properties of sandwich beam. Furthermore, sound transmission loss of a sandwich plate was measured and the results were compared to the predicted ones. The agreement between predicted and experimental results have been found to be satisfactory.

\section{THEORY}

The sandwich material treated here consists of a thick light-weight core, bonded to two thin, stiff and stronger laminates. Both laminates and core are assumed to be isotropic. An analytical model is developed to predict the wave propagation constants in sandwich beam. The displacement of laminates is considered to follow Euler beam theory, in other words, only bending and longitudinal waves are included. On the other hand the wave propagation in the core is described through the general field equations (see [1]). Thus, bending, rotation and shear as well as longitudinal deflection are included through a combination of longitudinal and transverse waves. Using the continuity of displacements and stresses in the adjacent plates lead to a system of linear equations. Solving this system of linear equations gives wave propagation constants for the structure (see [3]). Having the propagation constants one can determine a so called equivalent bending stiffness for sandwich beam according to classic Euler beam theory:

$$
D=\left(\frac{m^{\prime} \omega^{2}}{\kappa}\right)^{4}
$$

where $m^{\prime}$ is the mass of the beam per unit length, $\kappa$ the wave propagation constant and $\omega$ the angular frequency. On the other hand for a freely suspended beam and also for a beam with clamped edges the bending stiffness can be expressed as a function of resonance frequency (c.f Cremer and Heckl [1], Nilsson [2]):

$$
D_{n}=\frac{M \omega_{n}^{2} L^{3}}{\left[(n+1 / 2) \pi+k_{n}\right]^{4}}
$$

where $L$ and $M$ are the length and the mass of the beam and $k_{n}$ is a mode number dependent constant. This quantity which is a good measure of dynamical properties of a sandwich beam is one of the objects of verification of our theory in this paper. Concerning the acoustical properties of sandwich material, using predicted wave propagation constants, one can determine the transmission loss (c.f Nilsson [2]).

\section{MEASUREMENTS}

For this research, proper modal analysis of the sandwich-beams is vital. In order to determine the natural frequencies and the modal parameters accurately, modal analysis was performed on a sandwich-beam, its core and its laminates. The sand wich-beam was made of GRP laminates and PVC core material.

The material properties and dimensions of sandwich-beam are listed in Table 1. 'I-DEAS Master Series' software was used for measurements and modal analysis. The boundary conditions included free edges $(F-F)$ and clamped edges $(C-C)$. The boundary condition $F-F$ was obtained by hanging the beam horizontally using threads. A clampedtype boundary condition for the beam was effected by compressing each end between a concrete slab, conforming to 
TA BLE 1. Dimensions and material parameters of sandwich beam.

\begin{tabular}{|c|c|c|c|c|c|c|c|}
\hline & $\begin{array}{c}\rho \\
\left(k g / m^{3}\right)\end{array}$ & $\begin{array}{c}E \\
\left(N / m^{2}\right)\end{array}$ & $\begin{array}{c}t \\
(m m)\end{array}$ & $\begin{array}{c}L \\
(m)\end{array}$ & $\begin{array}{c}b \\
(m m)\end{array}$ & $\begin{array}{c}\delta \\
(\%)\end{array}$ & $\nu$ \\
\hline Laminates(GRP) & 1580 & $9.8 \mathrm{E} 9$ & 2.5 & 1.65 & 116 & 1.8 & 0.4 \\
\hline Core(PVC) & 101 & 94 E 6 & 50 & 1.65 & 116 & 2.4 & 0.1 \\
\hline Aluminum & 2620 & $58 \mathrm{E} 9$ & 0.75 & 1.9 & 1.1 & 0.6 & 0.3 \\
\hline Core(Airex) & 88 & 62 E 6 & 12 & 1.9 & 1.1 & 1.0 & 0.12 \\
\hline Slimtec & 1583 & $4 \mathrm{E} 9$ & 1.2 & 1.9 & 1.1 & 10 & 0.45 \\
\hline
\end{tabular}

most of the beam perimeter, and a hard steel bracket, by means of threaded fasteners joining the bracket to grooves in the floor. A slight elevation step from slab's upper surface to the beams, permits this compression. The sandwich plate was composed of Aluminum and a kind of plastic called 'Slimtec' as laminates and 'Airex' as core. In order to get the material properties of the constituent materials of sandwich plate, modal analysis was performed on a beam shape of sandwich material. These measured properties and dimensions of sandwich-plate are listed in Table 1.

Sound reduction for the plate was measured. The measurments followed 'Nordtest Method NT ACOU084', International Standard ISO 9614-2, and the corresponding ISO 140 series standards.

\section{RESULTS}

The measured and predicted transmission loss for the sandwich plate can be found in figure 1(b). The estimation of this loss would be possible using wave propagation constants which are the solutions to wave equations [3]. The agreement between the measured and predicted results is satisfactory. Figure 1(a) depicts the measured so called

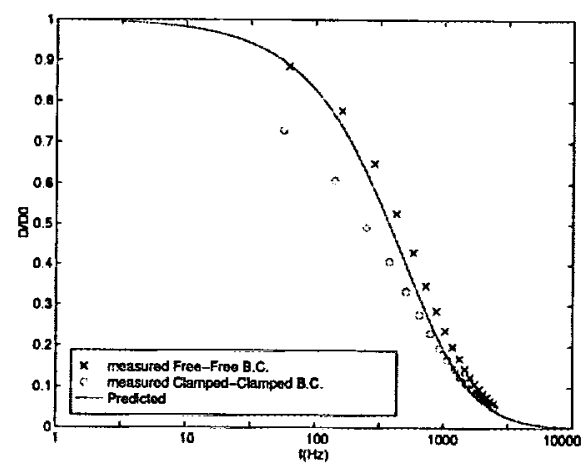

(a)

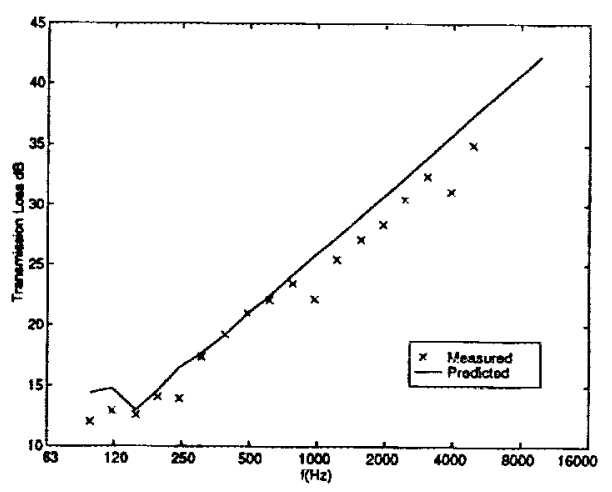

(b)

FIG URE 1. (a) Measured and predicted bending stiffness for a sandwich beam; (b) Measured and predicted transmission loss for a sandwich plate.

equivalent bending stiffnesses for $C \cdot C$ and $F \cdot F$ boundary conditions. The predicted bending stiffness, determined due the solution of wave equations [3], can also be obtained in the same figure. The most significant result in this figure is the difference between the two boundary conditions. One can obtain a decreased bending stiffness, up to $25 \%$ at $\approx 300 \mathrm{~Hz}$, for $C$ - $C$ boundary condition compared to the $F-F$ boundary condition.

\section{REFERENCES}

1. Cremer, L. and Heckl, M. Structure-borne Sound. Springer Verlag, Berlin, 1988.

2. Nilsson, A. C. Wave propagation in and sound transmission through sandwich plates. Journal of Sound and Vibration, 138(1):73-94, 1990.

3. Sander-Tavallaey, Shiva. Towards an analytical model of wave propagation in sandwich beams. In Proceedings ofthe 1996 International Congress on Noise Control Engineering: Internoise 96, volume 3, pages 1349-1352, Liverpool, UK, 1996. 